\title{
Kinetic Study of the Visible Light-Induced Sonophotocatalytic Degradation of MB Solution in the Presence of $\mathrm{Fe} / \mathrm{TiO}_{2}$-MWCNT Catalyst
}

\author{
Kan Zhang and Won-Chun $\mathrm{Oh}^{*}$ \\ Department of Advanced Materials \& Science Engineering, Hanseo University, Chungnam 356-706, Korea \\ *E-mail:wc_oh@hanseo.ac.kr \\ Received February 14, 2010, Accepted April 13, 2010

\begin{abstract}
In order to effective degradation of organic dye both under visible light or ultrasonic irradiation, the MWCNTs (multiwalled carbon nanotube) deposited with $\mathrm{Fe}$ and $\mathrm{TiO}_{2}$ were prepared by a modified sol-gel method. The Fe/TiO ${ }_{2}-$ MWCNT catalyst was characterized by surface area of BET, scanning electron microscope (SEM), Transmission Electron Microscope (TEM), X-ray diffraction (XRD), and energy dispersive X-ray (EDX) and ultraviolet-visible (UV-vis) spectroscopy. The low intensity visible light and low power ultrasound was as an irradiation source and the methylene blue $(\mathrm{MB})$ was choose as the model organic dye. Then degradation experiments were carried out in present of undoped $\mathrm{TiO}_{2}, \mathrm{Fe} / \mathrm{TiO}_{2}$ and $\mathrm{Fe} / \mathrm{TiO}_{2}-\mathrm{MWCNT}$ catalysts. Through the degradation of MB solution, the results showed the feasible and potential use of $\mathrm{Fe} / \mathrm{TiO}_{2}-\mathrm{MWCNT}$ catalyst under visible light and ultrasonic irradiation due to the enhanced formation of reactive radicals as well as the possible visible light and the increase of ultrasound-induced active surface area of the catalyst. After addition of $\mathrm{H}_{2} \mathrm{O}_{2}$, the $\mathrm{MB}$ degradation rates have been accelerated, especially with $\mathrm{Fe} / \mathrm{TiO}_{2}-$ MWCNT catalyst, in case of that the photo-Fenton reaction occurred. The sonophotocatalysis was always faster than the respective individual processes due to the more formation of reactive radicals as well as the increase of the active surface area of $\mathrm{Fe} / \mathrm{TiO}_{2}-\mathrm{MWCNT}$ catalyst.
\end{abstract}

Key Words: $\mathrm{Fe} / \mathrm{TiO}_{2}-\mathrm{MWCNT}$ catalyst, Ultrasound, Visible light, $\mathrm{MB}$

\section{Introduction}

Over the past several years, continuing interest has been focused on the application of advanced oxidation processes (AOP's) for the treatment of hazardous organic pollutants in water. Of the various AOP's (photocatalysis, ozonization or Fenton-like processes) commonly used for wastewater treatment, which has been paid to the use of ultrasound as one of the effective technologies. ${ }^{1,2}$ In 1894, the effects of ultrasound waves were first observed and when researchers irradiated water with ultrasound, they discovered that heat generated from the cavity implosion degrades water $\left(\mathrm{H}_{2} \mathrm{O}\right)$ into extremely reactive hydrogen atoms $\left(\mathrm{H}^{\circ}\right)$ and hydroxyl radicals $\left(\mathrm{OH}^{*}\right){ }^{3}$ Cavity implosion caused localized temperatures and pressures (inside the bubble) to reach values as high as $5000 \mathrm{~K}$ and $1000 \mathrm{~atm}$, respectively. Generally, it is accepted that the generation of highly reactive species such as hydroxyl $\left(\mathrm{OH}^{\circ}\right)$, and hydrogen $\left(\mathrm{H}^{\circ}\right)$ radicals are formed under these extreme conditions. ${ }^{4-6}$

At the same time, some researchers began to use a semiconductor powder (usually as $\mathrm{TiO}_{2}$ ) to degrade organic pollutants under ultraviolet irradiation. ${ }^{7-9}$ However, first, because of the wide band gap of $\mathrm{TiO}_{2}$, its practical application is limited for the need of an ultraviolet excitation source. Second, due to high recombination rate of the photogenerated electrons and holes, its photocatalytic activity is lower. Therefore, in order to solve these problems, the effects of some metal and nonmetal as dopants such as $\mathrm{Fe}, \mathrm{Pt}, \mathrm{Ag}, \mathrm{C}$ and $\mathrm{S}$ were already investigated. ${ }^{10-14}$ Especially, $\mathrm{C}$ and $\mathrm{Fe}$ co-doped $\mathrm{TiO}_{2}$ showed higher activity than pristine $\mathrm{TiO}_{2}$ in multiple uses. ${ }^{15}$ Another previous research also showed two dopants had more beneficial effect than a single one for improving adsorption ability and photocatalytic activity. ${ }^{16}$ In recent years, several literatures ${ }^{17,18}$ have been developed for
$\mathrm{MWCNT} / \mathrm{TiO}_{2}$ and $\mathrm{Fe}-\mathrm{TiO}_{2}$ catalyst, which can occur results in higher photocatalytic activity with respect to that of undoped $\mathrm{TiO}_{2}$ under visible light irradiation.

However, it is very difficult to treat those non- or low-transparent wastewaters using photocatalytic degradation method due to low penetrating ability of any kinds of light sources. Whereas, the penetrating ability of ultrasound is very strong for any water medium and its penetrating depth can ordinarily attain to $25-30 \mathrm{~cm}$. Tuziuti et al. ${ }^{19}$ determined that the presence of the $\mathrm{TiO}_{2}$ particles contributed to an increase in bubble cavitation which promotes the transfer of the generated free radicals to the liquid bulk region as the bubble collapses. An ultrasonic irradiation might be used for formation of hydroxyl $\left(\mathrm{OH}^{\circ}\right)$ radical. Hence, the ultrasonic irradiation has been proposed as one of the techniques for degradation of hazardous organic dyes. Unfortunately, the method depends on a strong power supply and long irradiation time, which usually needs lots of energy costly treated equipment. In fact, in order to overcome the low penetrating ability of light, some transition metal as $\mathrm{Fe}, \mathrm{Co}$ and $\mathrm{Cr}$ doped $\mathrm{TiO}_{2}$ sonocatalysts have been developed. ${ }^{20,21}$ In addition, little attention has been focused on coupling ultrasound with photocatalytic, the simultaneous use of sonocatalytic and photocatalytic was called sonophotocatalytic, which had been used to degrade organic pollutants. ${ }^{22,23}$

The aim of this work is to prove a high photo-, sonocatalytic activity and sonophotocatalytic on MWCNT deposited with Fe and $\mathrm{TiO}_{2}$, employed under normal atmosphere in the absence of any oxidant chemical species, in the degradation and mineralization of MB solution. Following recent our studies ${ }^{24,25}$ on use of photocatalysis in degradation of various dyes, possible synergistic effects between Fe particles and one kind of carbon in degradation of $\mathrm{MB}$ under ultrasonic irradiation with low frequency 
ultrasound have been checked in the present work. This attempt, if proved successful, will be a typical example for cooperative effects on photolysis, sonolysis and their combined application.

\section{Experimental}

Materials. As the support material, MWCNT were purchased from Carbon Nano-material Technology Co. (Korea), and used without further purification. $m$-chloroperbenzoic acid (MCPBA) was used as an oxidized reagent and purchased from Acros Organics (New Jersey, USA). Benzene (99.5\%), which was used as an organic solvent, was purchased from Samchun Pure Chemical Co., Ltd. (Korea). TNB $\left(\mathrm{C}_{16} \mathrm{H}_{36} \mathrm{O}_{4} \mathrm{Ti}\right)$, used as a titanium dioxide source for the preparation of the $\mathrm{Fe} / \mathrm{TiO}_{2}-\mathrm{MWCNT}$ catalyst was purchased from Aldrich Chemical Co., Ltd. (USA), and $\mathrm{Fe}\left(\mathrm{NO}_{3}\right)_{3} \cdot 9 \mathrm{H}_{2} \mathrm{O}$ as the ferric source was purchased from Duksan Pure Chemical Co., Ltd. (Korea). The MB (analytical grade $(\geq 99.99 \%)$ ) was purchased from Duksan Pure Chemical Co., Ltd. (Korea).

Preparation of samples. $\mathrm{Fe} / \mathrm{TiO}_{2}$ catalyst were prepared by TNB with aqueous solutions of $\mathrm{Fe}\left(\mathrm{NO}_{3}\right)_{3}$ by a sol-gel method. The $3 \mathrm{~mL}$ TNB was dissolved in $20 \mathrm{~mL}$ of benzene to prepare the TNB solution. The $5 \mathrm{~mL} 0.1 \mathrm{M} \mathrm{Fe}\left(\mathrm{NO}_{3}\right)_{3}$ solutions were slowly dropped into the TNB solution prepared and vigorously stirred at $353 \mathrm{~K}$ for $5 \mathrm{~h}$, the solution transformed to $\mathrm{Fe} / \mathrm{TiO}_{2}$ sol state, and then dried at $363 \mathrm{~K}$. Finally, the mixture was heat treated at $873 \mathrm{~K}$. For preparation of $\mathrm{Fe} / \mathrm{TiO}_{2}-\mathrm{MWCNT}$ catalyst, $2 \mathrm{~g} \mathrm{MCPBA}$ was dissolved in $80 \mathrm{~mL}$ benzene for preparing the oxidizing agent. Then, $20 \mathrm{mg}$ MWCNT powder was put into the oxidizing agent solution, refluxed at $353 \mathrm{~K}$ for $6 \mathrm{~h}$. The solid precipitates formed were dried at $363 \mathrm{~K}$. The oxidized MWCNT was added to the same amount of $\mathrm{Fe}\left(\mathrm{NO}_{3}\right)_{3}$ solutions as $\mathrm{Fe} / \mathrm{TiO}_{2}$ catalyst prepared, and the mixtures were stirred for $24 \mathrm{~h}$ using a non-magnetic stirrer at room temperature. After the heat treatment at $773 \mathrm{~K}$, we obtained the Fe-MWCNT. The Fe-MWCNT was put into the TNB solution prepared as above and then the mixed solution was stirred for $5 \mathrm{~h}$ in an air atmosphere. After stirring the solution transformed to gel state, and these gels were reacted at $873 \mathrm{~K}$ for $1 \mathrm{~h}$. Then, the $\mathrm{Fe} / \mathrm{TiO}_{2}-\mathrm{MWCNT}$ catalyst was obtained. The procedure of prepared samples is showed in Fig. 1. In addition, the commercial $\mathrm{TiO}_{2}$ samples were chosen to compare with samples prepared.

Characteristics of the samples. The BET surface area by $\mathrm{N}_{2}$ adsorption method was measured at $77 \mathrm{~K}$ using a BET analyzer (Monosorb, USA). XRD (Shimadz XD-D1, Japan), the result was used to identify the crystallinity with $\mathrm{Cu} \mathrm{K} \alpha$ radiation. SEM (JSM-5200 JOEL, Japan) was used to observe the surface state and structure of the $\mathrm{Fe} / \mathrm{TiO}_{2}$-nanocarbon catalyst. TEM (JEOL, JEM-2010, Japan) at an acceleration voltage of $200 \mathrm{kV}$ was used to investigate the size and distribution of the MWCNT deposited with ferric and titanium samples. EDX spectra were also obtained to determine the elemental information of $\mathrm{Fe} / \mathrm{TiO}_{2}-\mathrm{MW}-$ CNT catalyst. UV-vis absorption parameters for the MB solution degraded by $\mathrm{Fe} / \mathrm{TiO}_{2}$ and $\mathrm{Fe} / \mathrm{TiO}_{2}-\mathrm{MWCNT}$ catalyst were recorded by a UV-vis (Optizen Pop Mecasys Co., Ltd., Korean) spectrophotometer. The visible light source was an 8W LED lamp ( $\lambda<420 \mathrm{~nm}$, Fawoo Technology, Korea), and Controllable Serial-Ultrasonics apparatus (DH-WUC-A02H, Korea) was

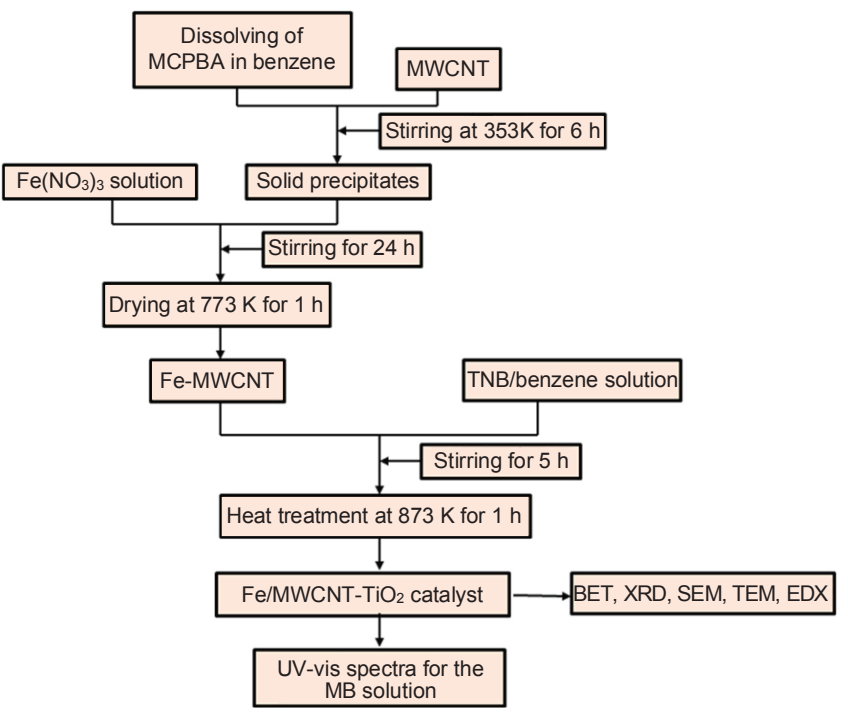

Figure 1. The preparation procedure of $\mathrm{Fe} / \mathrm{TiO}_{2}-\mathrm{MWCNT}$ catalyst.

adopted to irradiate the MB solutions, operating at an ultrasonic frequency of $28 \mathrm{kHz}$ and an output power of $50 \mathrm{~W}$ through manual adjusting.

Photocatalytic activity of samples. The sonocatalytic degradation was tested by $\mathrm{Fe} / \mathrm{TiO}_{2}$ and $\mathrm{Fe} / \mathrm{TiO}_{2}-\mathrm{MWCNT}$ catalyst powder with ultrasonic generators and operated with a fixed frequency of $28 \mathrm{kHz}$. The reactions were carried out in an open cylindrical stainless glass vessel. The photocatalytic degradation was tested by $\mathrm{Fe} / \mathrm{TiO}_{2}$ and $\mathrm{Fe} / \mathrm{TiO}_{2}-\mathrm{MWCNT}$ catalyst powder and an aqueous solution of $\mathrm{MB}$ in a same glass vessel and irradiation system with visible light. The $\mathrm{Fe} / \mathrm{TiO}_{2}$ or $\mathrm{Fe} / \mathrm{TiO}_{2}-$ MWCNT catalyst $(0.05 \mathrm{~g})$ was suspended in $50 \mathrm{~mL}$ of MB solution with a concentration of $c a .1 .0 \times 10^{-5} \mathrm{M}$ in the glass vessel. Then, the mixed solution was placed in the dark for at least $2 \mathrm{~h}$ in order to establish an adsorption-desorption equilibrium, which was hereafter considered as the initial concentration $\left(\mathrm{c}_{0}\right)$ after dark adsorption. Experiments were then carried out under visible light, ultrasonic irradiation and visible light-ultrasonic irradiation respectively. All tests were performed at room temperature under atmospheric pressure. After irradiation time of $0 \mathrm{~min}, 30$ $\mathrm{min}, 60 \mathrm{~min}, 90 \mathrm{~min}$, and $120 \mathrm{~min}, 10 \mathrm{~mL}$ of solution was taken out and immediately centrifuged to separate any suspended solid. The clean transparent solution was analyzed using a UVvis spectrophotometer. The blue color of the solution faded gradually with time due to the adsorption and degradation of MB. And then the concentration of MB in the solution was determined as a function of irradiation time from the absorbance change at a wavelength of $660 \mathrm{~nm}$.

\section{Results and Discussion}

Some morphology of $\mathrm{Fe} / \mathrm{TiO}_{2}$ and $\mathrm{Fe} / \mathrm{TiO}_{2}-\mathrm{MWCNT}$ catalyst. The values of BET surface area of pure $\mathrm{TiO}_{2}, \mathrm{Fe} / \mathrm{TiO}_{2}$ and $\mathrm{Fe} / \mathrm{TiO}_{2}-\mathrm{MWCNT}$ catalysts are presented in Table 1 . As the results of Table 1 shown, the BET surface areas of pristine $\mathrm{TiO}_{2}$ and $\mathrm{Fe}-\mathrm{TiO}_{2}$ were 8.3 and $11.9 \mathrm{~m}^{2} / \mathrm{g}$, respectively. While the BET surface an area of $\mathrm{Fe} / \mathrm{TiO}_{2}-\mathrm{MWCNT}$ increased to 58.7 
Table 1. BET surface area and EDX elemental microanalysis (wt \%) of pure $\mathrm{TiO}_{2}, \mathrm{Fe} / \mathrm{TiO}_{2}$ and $\mathrm{Fe} / \mathrm{TiO}_{2}-\mathrm{MWCNT}$ catalysts.

\begin{tabular}{lccccc}
\hline \multirow{2}{*}{ Samples } & \multirow{2}{*}{$\begin{array}{c}\mathrm{S}_{\mathrm{BET}} \\
\left(\mathrm{m}^{2} / \mathrm{g}\right)\end{array}$} & \multicolumn{4}{c}{ Elements $(\mathrm{wt} \%)$} \\
\cline { 3 - 6 } & 11.9 & 0.00 & 55.5 & 43.4 & 1.11 \\
\hline $\mathrm{Fe}\left(\mathrm{NO}_{3}\right)_{3}+\mathrm{TNB}$ & 58.7 & 22.5 & 36.8 & 39.6 & 1.10 \\
$\mathrm{MWCNT}+\mathrm{Fe}\left(\mathrm{NO}_{3}\right)_{3}+\mathrm{TNB}$ & $\mathrm{Ci}$ & $\mathrm{Fe}$ \\
${\mathrm{Pure} \mathrm{TiO}_{2}}$ & 8.30 & 0 & 19.57 & 80.43 & 0
\end{tabular}
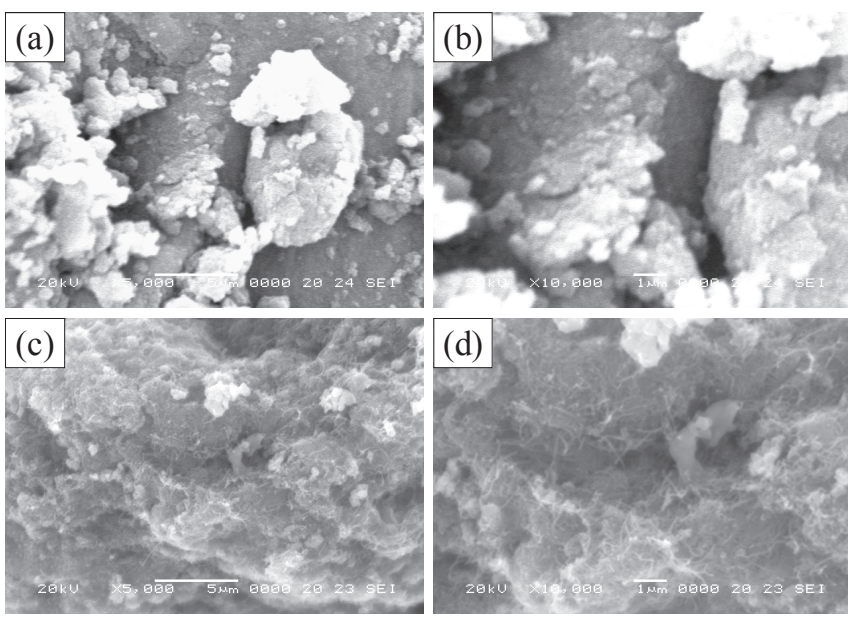

Figure 2. $\mathrm{SEM}$ micrographs of $\mathrm{Fe} / \mathrm{TiO}_{2}$ and $\mathrm{Fe} / \mathrm{TiO}_{2}-\mathrm{MWCNT}$ catalysts: $\mathrm{Fe} / \mathrm{TiO}_{2}$ : (a) $\times 5000$, (b) $\times 10000$ and $\mathrm{Fe} / \mathrm{TiO}_{2}-\mathrm{MWCNT}$ : (c) $\times 5000$, (d) $\times 10000$.

$\mathrm{m}^{2} / \mathrm{g}$, when $\mathrm{TiO}_{2}$ and $\mathrm{Fe}$ components were both introduced in CNT matrix. It can be evidently seen that there was a large change of the micropore size distribution for $\mathrm{Fe} / \mathrm{TiO}_{2}-\mathrm{MWCNT}$ catalyst compared to that of corresponding $\mathrm{TiO}_{2}$. This indicated that large surface areas of $\mathrm{Fe} / \mathrm{TiO}_{2}-\mathrm{MWCNT}$ catalyst were directly related to high adsorption ability.

SEM images of the $\mathrm{Fe} / \mathrm{TiO}_{2}$ and $\mathrm{Fe} / \mathrm{TiO}_{2}-\mathrm{MWCNT}$ catalyst are shown in Fig. 2. Fig. 2 (a) and (b) showed the SEM images of Fe doped $\mathrm{TiO}_{2}$ nanoparticles, it is clear that the grains with unequal size particles were coherent together. The obtained results confirmed that the $\mathrm{Fe} / \mathrm{TiO}_{2}$ catalyst is composed of densely packed flat pieces with aggregation of nanoparticle $\mathrm{TiO}_{2}$. The morphological characterization of the $\mathrm{Fe} / \mathrm{TiO}_{2}-\mathrm{MWCNT}$ catalyst is presented in Fig. 2 (c) and (d). It was observed that MWCNT is covered with $\mathrm{TiO}_{2}$ particles. These homogenous $\mathrm{TiO}_{2}$ particles were uniformly dispersed on MWCNT surface and some small bundles were found with irregular agglomerate dispersion. It was well explained that the good dispersion of small particles were not well homogenized during the vigorous stirring. Moreover, an obvious advantage of the oxidized MWCNT using MCPBA was that a considerable portion of $\mathrm{TiO}_{2}$ would be enclosed in the three-dimensional matrix. ${ }^{26}$

TEM images of $\mathrm{Fe} / \mathrm{TiO}_{2}$ and $\mathrm{Fe} / \mathrm{TiO}_{2}-\mathrm{MWCNT}$ catalysts are shown in Fig. 3. TEM images of $\mathrm{Fe} / \mathrm{TiO}_{2}$ catalyst are given in Fig. 3 (a) and (b), which showed that the catalyst were consisted of Fe nanoparticles and $\mathrm{TiO}_{2}$ clusters. The black dots can correspond to the deposition of the Fe nanoparticles, which was grew on the outer and inner surface of $\mathrm{TiO}_{2}$ with size about $10 \sim$
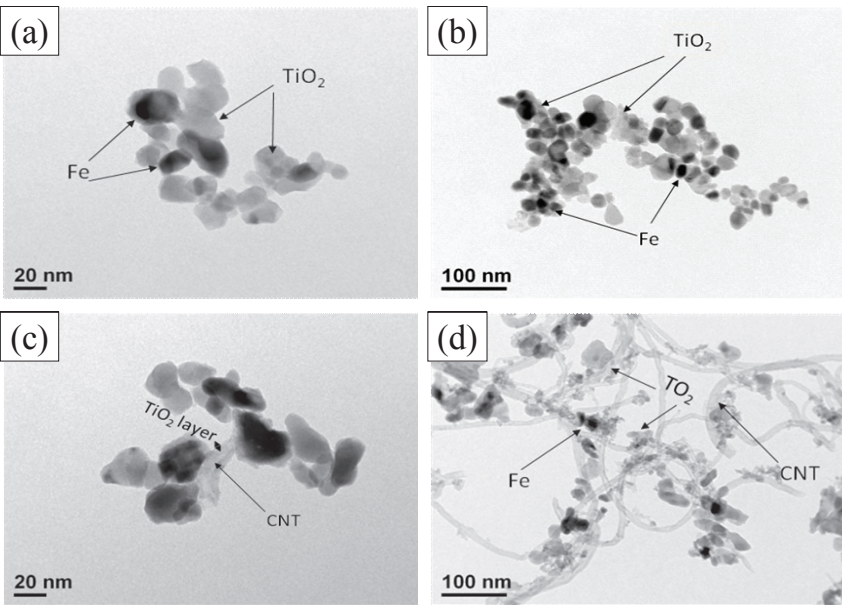

Figure 3. TEM micrograph of the $\mathrm{Fe} / \mathrm{TiO}_{2}$ and $\mathrm{Fe} / \mathrm{TiO}_{2}-\mathrm{MWCNT}$ catalysts: (a) and (b): $\mathrm{Fe} / \mathrm{TiO}_{2}$, (c) and (d): $\mathrm{Fe} / \mathrm{TiO}_{2}-\mathrm{MWCNT}$.

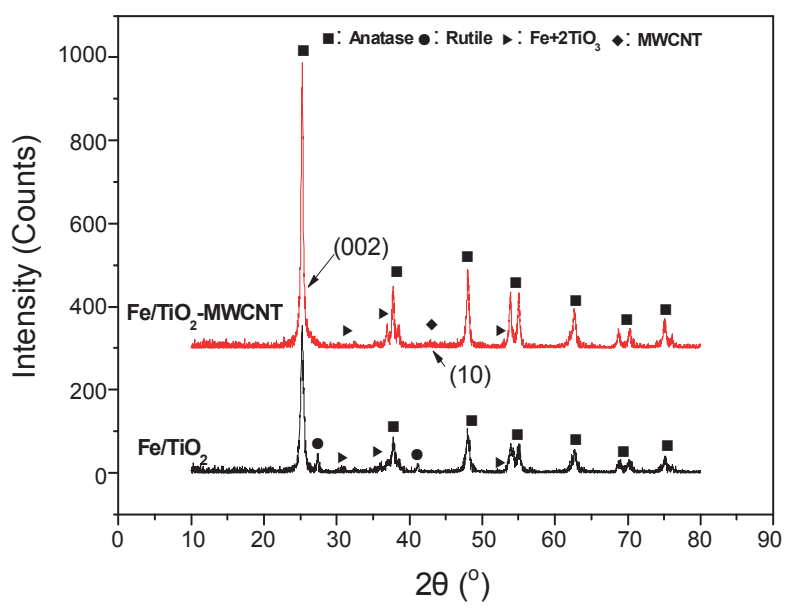

Figure 4. $\mathrm{XRD}$ patterns of $\mathrm{Fe} / \mathrm{TiO}_{2}$ and $\mathrm{Fe} / \mathrm{TiO}_{2}-\mathrm{MWCNT}$ catalysts.

$20 \mathrm{~nm}$. The $\mathrm{Fe} / \mathrm{TiO}_{2}-\mathrm{MWCNT}$ catalyst was investigated by TEM as shown in Fig. 3(c) and (d). All of the MWCNT were covered with a dense layer of $\mathrm{TiO}_{2}$ particles, and no free MWCNT were found. The $\mathrm{TiO}_{2}$ nanoparticles deposited on MWCNT surface showed a strong interphase structure and the particle size was uniform, which indicated that $\mathrm{TiO}_{2}$ particles can be dispersed tightly on the surface of CNT. The binding between $\mathrm{TiO}_{2}$ and MWCNT surface is tight enough to resist repeated ultrasonication processes. In addition, a homogeneous dispersion of $\mathrm{TiO}_{2}$ in MWCNT matrix implied a possible disappearance of MWCNT characteristic peaks in their XRD patterns.

XRD patterns of the $\mathrm{Fe} / \mathrm{TiO}_{2}$ and $\mathrm{Fe} / \mathrm{TiO}_{2}-\mathrm{MWCNT}$ catalyst are given in Fig. 4. The most intense peaks of MWCNT correspond to the (002) reflection. The additional peaks present in all the diffractograms correspond to the single anatase form of $\mathrm{TiO}_{2}$. The (002) reflection of nanocarbon overlaps with the anatase (101) reflection. It illuminated that the MWCNT in Fe/ $\mathrm{TiO}_{2}-\mathrm{MWCNT}$ catalyst were coated with a typical single anatase crystallites. In XRD patterns of the $\mathrm{Fe} / \mathrm{TiO}_{2}$, significant diffraction peaks of rutile-phase $\mathrm{TiO}_{2}$ were detected. It reflected that MWCNT can suppress phase transformation from anatase 
(a)

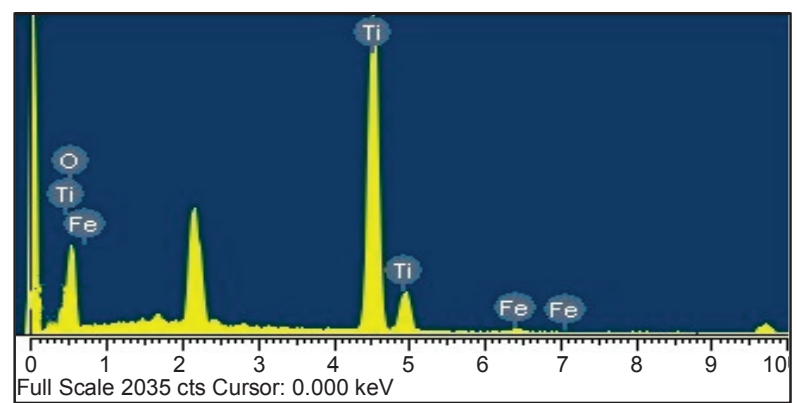

(b)

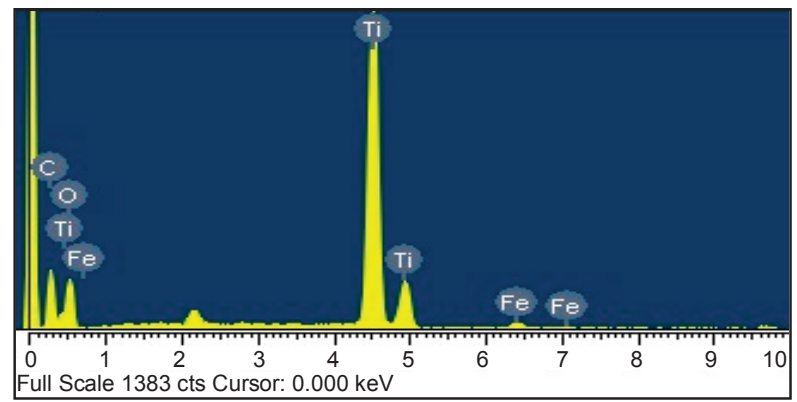

Figure 5. EDX elemental microanalysis of $\mathrm{Fe} / \mathrm{TiO}_{2}$ and $\mathrm{Fe} / \mathrm{TiO}_{2}-$ MWCNT catalysts: (a) $\mathrm{Fe} / \mathrm{TiO}_{2}$ and (b) $\mathrm{Fe} / \mathrm{TiO}_{2}-\mathrm{MWCNT}$.

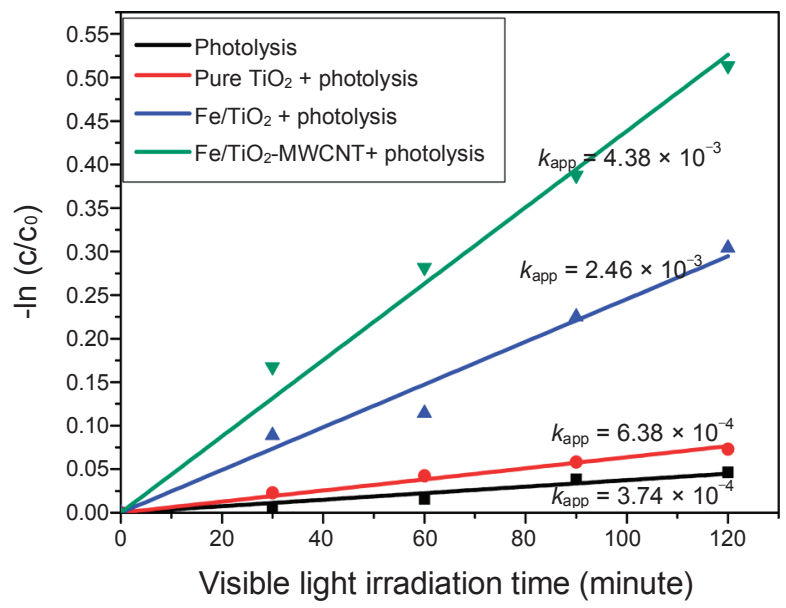

Figure 6. Visible light induced-degradation of $\mathrm{MB}$ on pure $\mathrm{TiO}_{2}, \mathrm{Fe} /$ $\mathrm{TiO}_{2}$ and $\mathrm{Fe} / \mathrm{TiO}_{2}-\mathrm{MWCNT}$ catalysts.

to rutile during heat treatment at high temperature. According to the former study, ${ }^{27}$ different phases of $\mathrm{TiO}_{2}$ behave differently in the case of photocatalysis and generally anatase phase is desirable. In addition, it was noteworthy that a weak ' $\mathrm{FeO}+2 \mathrm{TiO}_{3}$ ' peaks appeared in both of $\mathrm{Fe} / \mathrm{TiO}_{2}$ and $\mathrm{Fe} / \mathrm{TiO}_{2}-\mathrm{MWCNT}$ catalysts.

Fig. 5 shows the results of the $\mathrm{EDX}$ for $\mathrm{Fe} / \mathrm{TiO}_{2}$ and $\mathrm{Fe} / \mathrm{TiO}_{2}-$ MWCNT catalyst. These spectra showed the presence of peaks from the $\mathrm{C}, \mathrm{O}, \mathrm{Ti}$ and $\mathrm{Fe}$ elements. And, the numerical contents for various elements are listed in the Table 3. It showed that the quantities of carbon and $\mathrm{Fe}$ in the $\mathrm{Fe} / \mathrm{TiO}_{2}$ and $\mathrm{Fe} / \mathrm{TiO}_{2}-\mathrm{MWC}$ NT catalyst are small with a major element of Ti. According to former studies, ${ }^{28,29}$ the higher concentration of dopant in $\mathrm{TiO}_{2}$ matrix can be detrimental in formation of hole/electron recombination centers and an increase of negative charge capabilities.

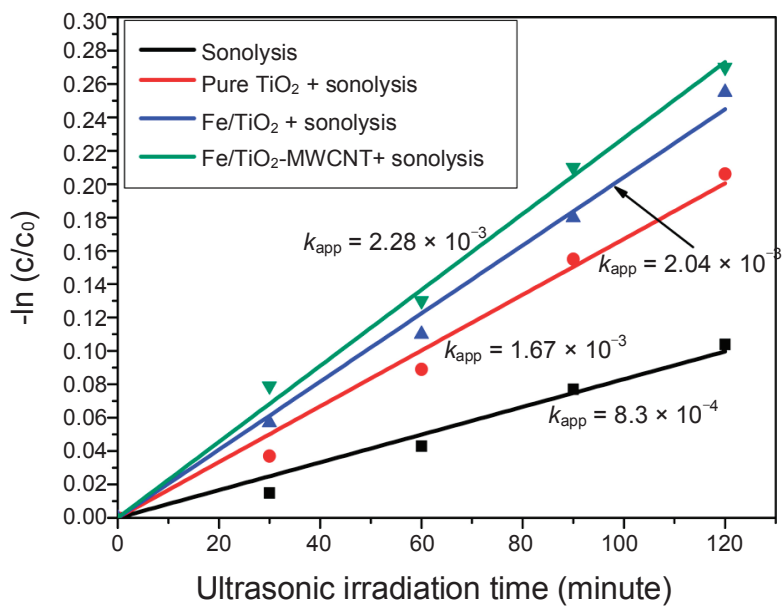

Figure 7. Sonodegradation of $\mathrm{MB}$ under ultrasonic irradiation on pure $\mathrm{TiO}_{2}, \mathrm{Fe} / \mathrm{TiO}_{2}$ and $\mathrm{Fe} / \mathrm{TiO}_{2}-\mathrm{MWCNT}$ catalysts.

The effect of visible light and ultrasonic irradiation time for degradation of MB. Fig. 6 shows the photocatalytic conversion of $\mathrm{MB}$ over pure $\mathrm{TiO}_{2}, \mathrm{Fe} / \mathrm{TiO}_{2}$ and $\mathrm{Fe} / \mathrm{TiO}_{2}-\mathrm{MWCNT}$ catalyst under the visible light irradiation. More MB photodegradation was achieved in the $\mathrm{Fe} / \mathrm{TiO}_{2}$ catalyst as compared to that in the pure $\mathrm{TiO}_{2}$ catalyst. It means that the $\mathrm{Fe}$ doped $\mathrm{TiO}_{2}$ catalyst can overcome the lower activity under visible light irradiation. In addition, it was observed that the degradation ratio of the $\mathrm{Fe} /$ $\mathrm{TiO}_{2}-\mathrm{MWCNT}$ catalyst is greater than that of the $\mathrm{Fe} / \mathrm{TiO}_{2}$ for degradation of MB. This suggested that the combining way between MWCNT deposited with $\mathrm{Fe}$ and $\mathrm{TiO}_{2}$ should be taken into account to future enhance the photocatalytic activity, which was ascribed to that the introduction of MWCNT can be definitely benefit for photocatalytic activity.

The experimental conditions in the presence of pure $\mathrm{TiO}_{2}$ were same as that in the present of $\mathrm{Fe} / \mathrm{TiO}_{2}$ and $\mathrm{Fe} / \mathrm{TiO}_{2}-\mathrm{MW}$ CNT catalyst under ultrasonic irradiation. The relative concentration of $\mathrm{MB}$ in the aqueous solution is shown in Fig. 7. It indicated that all calculated values of $-\ln \left(\mathrm{C} / \mathrm{C}_{0}\right)$ are approximately linear with the irradiation time all through. Therefore, the sonocatalytic degradation processes of $\mathrm{MB}$ on these five sonocatalytic points obey the first-order kinetics reactions. Moreover, it was observed that the presence of pure $\mathrm{TiO}_{2}$ is more effective than absence of $\mathrm{TiO}_{2}$ since high degradation rate is achieved. It can be considered that the ultrasounds with a frequency of 28 $\mathrm{kHz}$ is like suitable energy source to inject electrons into the conduction band and to leave holes in the valence band behind by furnishing energy matching or exceeding the band gap energy of the catalyst. The holes are responsible to effectively form hydroxyl free radicals. The proposed reactions were showed in the equations ((1) - (3)):

$$
\begin{aligned}
& \left.\left.\mathrm{H}_{2} \mathrm{O}+\mathrm{TiO}_{2}+\right)\right) \text { ) (ultrasound) } \rightarrow \mathrm{OH}^{\bullet}+\mathrm{H}^{\bullet} \\
& \left.\left.\mathrm{O}_{2}+\mathrm{TiO}_{2}+\right)\right) \text { ) (ultrasound) } \rightarrow \mathrm{O}_{2}^{\cdot} \\
& \mathrm{O}_{2}^{\cdot}+\mathrm{H}_{2} \mathrm{O} \rightarrow 2 \mathrm{OH}^{\cdot}
\end{aligned}
$$

Thus, the presence of $\mathrm{TiO}_{2}$ can significantly accelerate the 


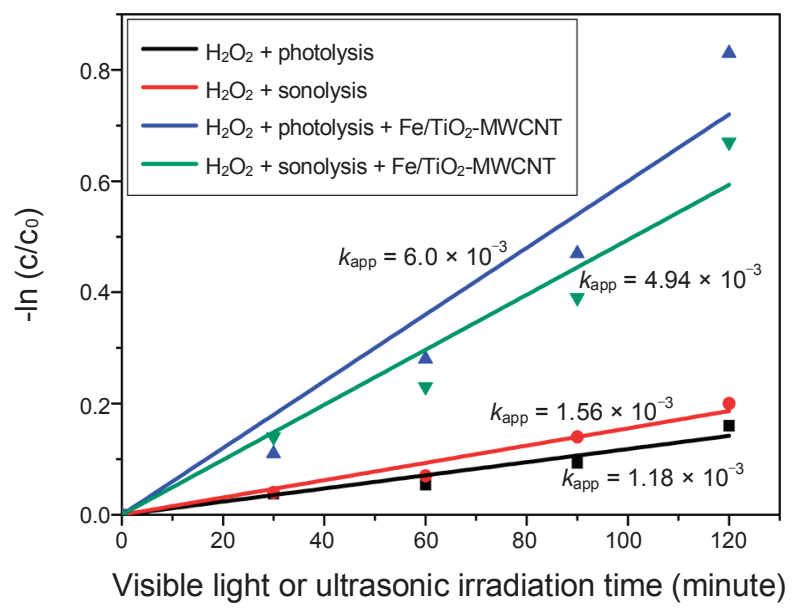

Figure 8. Degradation of $\mathrm{MB}$ on visible light and ultrasonic irradiation time with $\mathrm{H}_{2} \mathrm{O}_{2}$ for the $\mathrm{FeTiO}_{2}-\mathrm{MWCNT}$ catalysts.

generation of hydroxyl free radicals as compared to that caused by the sonolysis alone. In comparison of different catalysts among $\mathrm{TiO}_{2}, \mathrm{Fe} / \mathrm{TiO}_{2}$ and $\mathrm{Fe} / \mathrm{TiO}_{2}-\mathrm{MWCNT}$, it can be clearly found that sonodegradation effect in the presence of $\mathrm{Fe} / \mathrm{TiO}_{2}-$ MWCNT catalyst is best.

Influence of $\mathrm{H}_{2} \mathrm{O}_{2}$ on $\mathrm{Fe} / \mathrm{TiO}_{2}-\mathrm{MWCNT}$ catalyst under visible light and ultrasonic imadiation. In recent years, homogeneous photocatalysis of in presence of iron ion has received considerably. ${ }^{30-32}$ This is due to the photo-Fenton reaction, when the lack of mass transfer is limits, which are typically encountered in heterogeneous processes by coupling with hydrogen peroxide to establish the circulatory photo-Fenton system. ${ }^{25,33,34}$ Therefore, it was decided to investigate the effect of photo-Fenton reaction on $\mathrm{Fe} / \mathrm{TiO}_{2}-\mathrm{MWCNT}$ catalyst by degradation of $\mathrm{MB}$ under visible light and ultrasound irradiation, respectively. The degradation behaviors with the addition of $1.5 \times 10^{-3} \mathrm{~mol} \mathrm{H}_{2} \mathrm{O}_{2}$ are shown in Fig. 8. When $\mathrm{H}_{2} \mathrm{O}_{2}$ was only added to the $\mathrm{MB}$ solution without any photocatalyst, degradation of $\mathrm{MB}$ was progressed fast, even faster than in the presence of $\mathrm{TiO}_{2}$. It can be pointed out that hydrogen peroxide react with hydrogen to regenerate hydroxyl radicals by escape of free radicals from the interface under ultrasound irradiation:

$$
\left.\left.\mathrm{H}^{\bullet}+\mathrm{H}_{2} \mathrm{O}_{2}+\right)\right) \text { ) (ultrasound) } \rightarrow \mathrm{OH}^{\bullet}+\mathrm{H}_{2} \mathrm{O}
$$

The photo-Fenton degradation mechanism under visible light irradiation has been studied relatively clear. ${ }^{31}$ Since the MB molecular was excited under visible light, the photo-Fenton reaction can be occurred by Eq. ((5)-(7)):

$$
\begin{aligned}
& \mathrm{MB}+\mathrm{hv} \rightarrow \mathrm{MB}^{*} \text { (visible light) } \\
& \mathrm{MB}^{*}+\mathrm{Fe}^{3+} \rightarrow \mathrm{MB}^{+}+\mathrm{Fe}^{2+} \\
& \mathrm{Fe}^{2+}+\mathrm{H}_{2} \mathrm{O}_{2} \rightarrow \mathrm{Fe}^{3+}+\mathrm{OH}^{-}+\mathrm{OH}^{\cdot}
\end{aligned}
$$

The photo-Fenton reaction under visible light irradiation involved dye excitation and electron transfer from excited dye

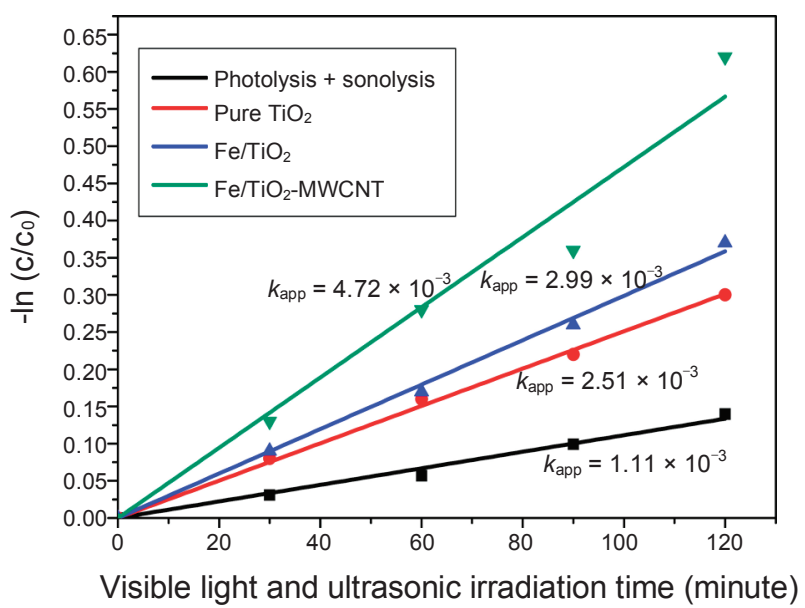

Figure 9. Sonophotodegradation of $\mathrm{MB}$ on pure $\mathrm{TiO}_{2}, \mathrm{Fe} / \mathrm{TiO}_{2}$ and $\mathrm{Fe} /$ $\mathrm{TiO}_{2}$-MWCNT catalysts.

molecules to $\mathrm{Fe}^{3+}$ ions, then which were reduced to $\mathrm{Fe}^{2+}$ ions. And then the generated $\mathrm{Fe}^{2+}$ ion reacted with $\mathrm{H}_{2} \mathrm{O}_{2}$ to form $\mathrm{OH}^{\circ}$ radicals.

The efficiency of the photo-Fenton reaction under ultrasound irradiation is similarly related to iron participating in the following redox processes in Eq. (7) and (8):

$$
\left.\left.\mathrm{Fe}^{3+}+\mathrm{OH}^{-}+\right)\right) \text {) (ultrasound) } \rightarrow \mathrm{Fe}^{2+}+\mathrm{OH}^{\bullet}
$$

Two hydroxyl radicals $\left(\mathrm{OH}^{\circ}\right)$ generated can be indirectly attributed to $\mathrm{H}_{2} \mathrm{O}_{2}$ decomposed by ultrasound. The presence in $\mathrm{Fe} /$ $\mathrm{TiO}_{2}$-MWCNT catalyst caused the degradation of $\mathrm{MB}$ was more progressed fast by powerful $\mathrm{H}_{2} \mathrm{O}_{2}$ assisting photo-Fenton reaction under visible light and ultrasound irradiation.

Sonophotocatalytic degradation of MB. MB degradation by means of simultaneous visible light and ultrasound in the present of pure $\mathrm{TiO}_{2}, \mathrm{Fe} / \mathrm{TiO}_{2}$ and $\mathrm{Fe} / \mathrm{TiO}_{2}-\mathrm{MWCNT}$ catalyst is shown in Fig 9. Like sonolysis, the sonophotocatalysis also appear to follow a pseudo-first order kinetic. And the degradation results are similar to photolysis and sonolysis, namely, the sonophotocatalytic activity of $\mathrm{Fe} / \mathrm{TiO}_{2}-\mathrm{MWCNT}$ catalyst is better than that of pure $\mathrm{TiO}_{2}$ and $\mathrm{Fe} / \mathrm{TiO}_{2}$ catalyst. In comparison of photolysis, sonolysis and sono-photolysis, sonophotocatalytic degradation generally occurs faster than during the respective individual processes. The beneficial effect of coupling photolysis with sonolysis may be attributed to several reasons. First, increase the amounts of hydroxyl radicals $\left(\mathrm{OH}^{\circ}\right)$ by simultaneous photolysis and sonolysis. Second, enhance mass transfer of organics between the liquid phase and the catalyst surface. ${ }^{35}$ Third, excite catalyst by ultrasound-induced cavitation. Fourthly, increase surface area due to ultrasound de-aggregating catalyst particles. ${ }^{22}$

The activity of pure $\mathrm{TiO}_{2}, \mathrm{Fe} / \mathrm{TiO}_{2}$ and $\mathrm{Fe} / \mathrm{TiO}_{2}-\mathrm{MWCNT}$ catalyst was evaluated by comparing the apparent first order kinetics as shown below.

$$
\ln \left(\mathrm{C}_{\mathrm{t}} / \mathrm{C}_{0}\right)=k_{\mathrm{app}} \times \mathrm{t}
$$

where, $\mathrm{C}_{0}$ and $\mathrm{C}_{\mathrm{t}}$ is the initial concentration and the concentration of the $\mathrm{MB}$ at time $\mathrm{t}$, respectively $(\mathrm{M}), \mathrm{t}$ is the reaction time 
and $k_{\text {app }}$ is the pseudo first-order constant (M/min). The $k_{\text {app }}$ values for the all cases considered can be approximately obtained as illustrated on Fig. 6, 7, 8 and 9. It was noted that degradation rate kinetic of the inhomogeneous catalysts of $\mathrm{TiO}_{2}$ is compactable with introduction of Fe and MWCNT. Interestingly, there appears to be a synergistic effect between visible light and ultrasound irradiation in the presence of pure $\mathrm{TiO}_{2}$ since rate constants of the combined photolysis with sonolysis process were greater than the sum of the rate constants of the individual processes. On the contrary, the synergy effect of $\mathrm{Fe} / \mathrm{TiO}_{2}$ and $\mathrm{Fe} /$ $\mathrm{TiO}_{2}-\mathrm{MWCNT}$ catalyst by simultaneous photolysis and sonolysis was lower than that of individual processes. It could be attributed to that the adsorption ability of catalysts for degradation of $\mathrm{MB}$ is not neglected during reaction processes. Moreover, the addition of $\mathrm{H}_{2} \mathrm{O}_{2}$ could be more beneficial for degradation of MB than that of coupling photolysis with sonolysis.

Possible degradation mechanism for photolysis and sonolysis. It's well known that conduction band electrons ( $\mathrm{e}^{-}$) and valence band holes $\left(\mathrm{h}^{+}\right)$are generated on the surface of $\mathrm{TiO}_{2}$ when it is irradiated with UV light. Holes can react with surface hydroxyl ions or water to produce hydroxyl radicals $(\mathrm{OH} \cdot)$, while electrons can react with adsorbed molecular oxygen yielding superoxide anion radicals $\left(\mathrm{O}_{2}^{-} \cdot\right)$. The superoxide anion radicals act as oxidizing agents or as an additional source of hydroxyl radicals. Theoretically, the pure $\mathrm{TiO}_{2}$ cannot be excited by visible light because of the lower energy than the band gap. However, MB molecular can be converted to the cationic radical $\left(\mathrm{MB}^{+} \cdot\right)$ by self-photosensitized capability, since inject electrons to the conduction band of $\mathrm{TiO}_{2}$.

However, for sonolysis mechanism, until now, there has been no ready-made mechanism and satisfying explanation yet on the sonolysis of organic pollutants in the presence of various catalysts. Possibly, the following two points of view, namely, sonoluminescence and "hot spot", could be accepted to explain the sonolysis of organic dye in presence of $\mathrm{TiO}_{2}$ catalyst. ${ }^{2,36}$ First, the ultrasonic irradiation can form light with a comparatively wide wavelength range. It is well known that the wavelengths below $387 \mathrm{~nm}$ can excite the $\mathrm{TiO}_{2}$ particles to act as a photocatalyst, hence to bring hole and electron pairs. Subsequently, a great deal $\mathrm{OH}^{*}$ radicals with high oxidative activity formed on the surface of the $\mathrm{TiO}_{2}$ particles. Secondly, as well known, the temperature of "hot spot" produced by ultrasonic activation in water medium can achieve $10^{5 \circ} \mathrm{C}$ or $10^{6 \circ} \mathrm{C}$, such a high-temperature sufficiently brings many holes producing $\mathrm{OH}^{\circ}$ radicals on the surface $\mathrm{TiO}_{2}$ particles.

For $\mathrm{Fe} / \mathrm{TiO}_{2}$ composites, as has been described above, the $\mathrm{Fe}$ particles leads to enhanced photocatalytic activity under visible light due to narrowing of the band gap of $\mathrm{TiO}_{2}$ by introduction of a doping energy level. This implies that $\mathrm{Fe}$-doped $\mathrm{TiO}_{2}$ can be activated by visible light and generate more photoinduced electrons and holes to participate the reaction. ${ }^{37}$ In sonolysis process, the crystalline $\mathrm{TiO}_{2}$ can be also excited first by light or heat resulting from ultrasonic cavitation on $\mathrm{Fe} / \mathrm{TiO}_{2}$ composite. The generated light or heat can be transferred to yield the electron-hole $\left(\mathrm{e}^{-}\right.$and $\left.\mathrm{h}^{+}\right)$pairs on surface of $\mathrm{TiO}_{2}$. Afterward, the electrons are continuously excited by light or heat and further reacted with the oxygen adsorbed. Simultaneously, some electrons are captured by the $\mathrm{Fe}^{3+}$ ions doped. This process can retard
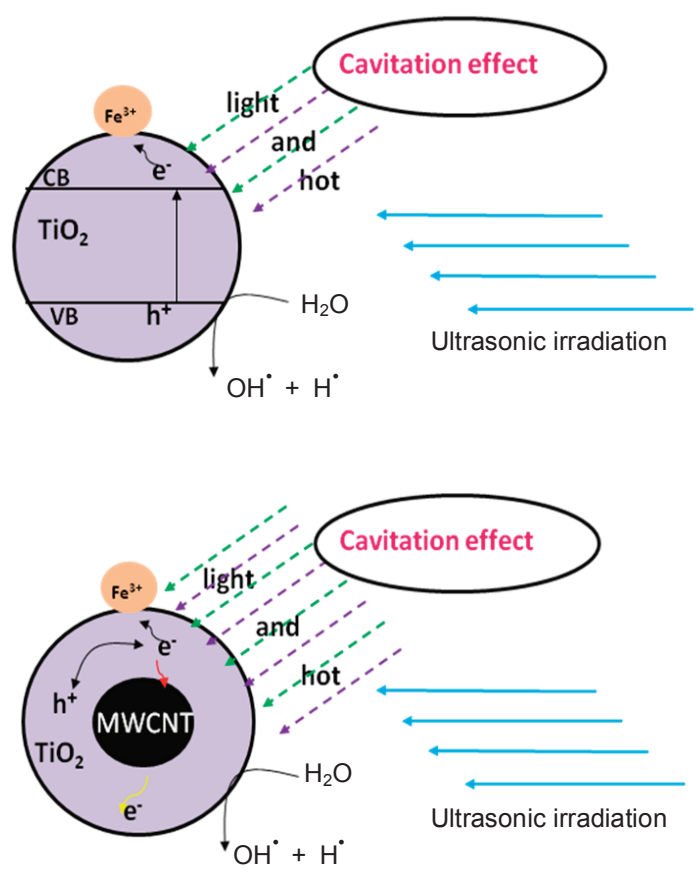

Figure 10. Possible exciton process of $\mathrm{Fe} / \mathrm{TiO}_{2}$ (a) and $\mathrm{Fe} / \mathrm{TiO}_{2}$ MWCNT (b) catalysts under ultrasonic irradiation.

combination rate of holes and electrons. The possible process is shown in Fig. 10 (a). So the sonocatalytic activity of $\mathrm{Fe} / \mathrm{TiO}_{2}$ composite is obviously improved by doping $\mathrm{Fe}^{3+}$ ion.

MWCNT as adsorbent and conductive material can absorb the light irradiation and transfer the photogenerated electron into the conduction band of $\mathrm{TiO}_{2}$ efficiently in photodegradation process. ${ }^{18}$ When $\mathrm{Fe} / \mathrm{MWCNT}-\mathrm{TiO}_{2}$ composite is illuminated with the visible light, some electrons are promoted from the valence band via MWCNT to the conduction band of the $\mathrm{TiO}_{2}$ to produce electron-hole $\left(\mathrm{e}^{-}\right.$and $\left.\mathrm{h}^{+}\right)$pairs. This electron transfer between MWCNT and $\mathrm{TiO}_{2}$ can be beneficial to enhance the photocatalytic activity of the composite. As mentioned above, the role played by MWCNT dopant can be illustrated by injecting electrons into $\mathrm{TiO}_{2}$ conduction band under visible light irradiation and triggering the formation of reactive sites, which were responsible for the degradation of the organic compound. The possible mechanisms of visible light induced reactions by Fe and $\mathrm{TiO}_{2}$ co-doped MWCNT composites are presented as follows:

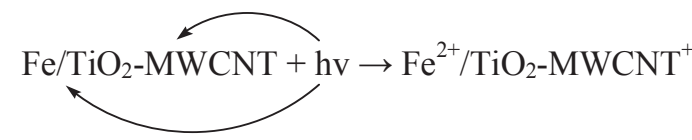

$$
\begin{aligned}
& \mathrm{TiO}_{2}-\mathrm{MWCNT}^{+} \rightarrow \mathrm{TiO}_{2}-\mathrm{MWCNT}+\mathrm{h}^{+} \\
& \mathrm{Fe}^{2+}+\mathrm{hv} \rightarrow \mathrm{Fe}^{3+}+\mathrm{e}^{-}
\end{aligned}
$$

The $\mathrm{Fe} / \mathrm{TiO}_{2}-\mathrm{MWCNT}$ with a high surface area gives rise to another type of synergy under ultrasonic irradiation. By using this $\mathrm{Fe}$ and $\mathrm{TiO}_{2}$ co-doped MWCNT sonocatalyst, the sonodegradation rate is increased by progressively allowing an in- 
creased quantity of the MB molecule to come in contact with the $\mathrm{TiO}_{2}$ through means of adsorption. This is significant that the most important $\mathrm{OH} \cdot$ generated on the surface of the $\mathrm{TiO}_{2}$ does not migrate very far from the active centers of the $\mathrm{TiO}_{2}$ coated on MWCNT. In this respect, the introduction of MWCNT promotes the adsorption of MB molecules and surface migration towards the catalytic sites as illustrated in Fig. 10 (b). This type of synergistic effect can be explained as an enhanced adsorption of the target $\mathrm{MB}$ molecules onto the carbon phase followed closely by a transfer through an interphase to the $\mathrm{TiO}_{2}$ phase, giving a complete sonodegradation process.

\section{Conclusion}

The MB dye in aqueous solution can be effectively degraded under visible light, ultrasonic irradiation and coupling the two processes combined with different catalysts. During degradation, the MWCNT deposited with $\mathrm{Fe} / \mathrm{TiO}_{2}$ catalyst showed much higher sonocatalytic activity than $\mathrm{Fe}$ doped $\mathrm{TiO}_{2}$ composite. Hence, the research results demonstrated the feasibilities of photo-, sonocatalytic and sonophotocatalytic degradation of $\mathrm{MB}$ and other organic pollutants in wastewaters. Especially, on the mechanism of sonocatalytic degradation in the presence of $\mathrm{Fe} / \mathrm{TiO}_{2}-\mathrm{MWCNT}$ composite and explained the reasons that the sonocatalytic activity was obviously enhanced due to fleet transfer of electrons and high surface area. The higher sonophotocatalytic activity may be attributed to the increased production of reactive free radicals as well as enhanced catalytic activity. In addition, the $\mathrm{Fe} / \mathrm{TiO}_{2}-\mathrm{MWCNT}$ catalyst seems to be beneficial for degradation of $\mathrm{MB}$ under visible light and ultrasonic irradiation with $\mathrm{H}_{2} \mathrm{O}_{2}$ respectively due to in presence of circulatory photo-Fenton system.

\section{References}

1. Berlan, J.; Trabelsi, F.; Delmas, H.; Wilhelm, A. M.; Petrignani, J. F. Ultrason. Sonochem. 1994, 1, 97.

2. Gogate, P. R. Adv. Environ. Res. 2002, 6, 335.

3. Suslick, K. S. Scientific American 1989, 260, 80.

4. Makino, K.; Mossoba, M. M.; Riesz, P. J. Phys. Chem. 1983, 87, 1369.

5. Serpone, N.; Colarusso, P. Res. Chem. Intermed. 1994, $20,635$.

6. Riesz, P.; Berdahl, D.; Christman, C. L. Environ. Health Perspect. 1985, 64, 233.

7. Silva, C. G.; Faria, J. L. J. Photochem. Photobiol. A 2003, 155, 133.

8. Han, W.; Zhu, W.; Zhang, P.; Zhang, Y.; Li, L. Catal. Today 2004, 90,319 .
9. Han, W.; Zhang, P.; Zhu, W.; Yin, J.; Li, L. Water. Res. 2004, 38 , 4197.

10. He, D. M.; Yang, L. X.; Kuang, S. Y.; Cai, Q. Y. Electrochem. Communications 2007, 9, 2467.

11. Zhang, X. W.; Zhou, M. H.; Lei, L. C. Mater. Chem. Phys. 2005, 91,73 .

12. Feng, J.; Wong, R. S. K.; Hu, X.; Yue, P. L. Catal. Today 2004, 98 , 441.

13. Wang, W. D.; Serp, P.; Kalck, P.; Faria, J. L. Appl. Catal. B: Environ. 2005, 56, 305 .

14. Ohno, T.; Akiyoshi, M.; Umebayashi, T.; Asai, K.; Mitsui, T.; Matsumura, M. Appl. Catal. A: General 2004, 265, 115.

15. Tryba, B. J. Hazard. Mater. 2008, 151, 623.

16. Yang, X.; Cao, C.; Hohn, K.; Erickson, L.; Maghirang, R.; Klabunde, K. J. Catal. 2007, 252, 296.

17. Teoh, W. Y.; Amal, R.; Mädler, L.; Pratsinis, S. E. Catal. Today 2007, 120, 203.

18. Wang, W. D.; Serp, P.; Kalck, P.; Faria, J. L. J. Mole. Catal. A: Chem. 2005, 235, 194.

19. Tuziuti, T.; Yasui, K.; Iida, Y.; Taoda, H.; Koda, S. Ultrason. 2004, $42,597$.

20. Wang, J.; Lv, Y. H.; Zhang, Z. H.; Deng, Y. Q.; Zhang, L. Q.; Liu, B.; Xu, R.; Zhang, X. D. J. Haz. Mater. 2009, 170, b398.

21. Wang, J.; Sun, W.; Zhang, Z. H.; Jiang, Z.; Wang, X. F.; Xu, R.; Li, R. H.; Zhang, X. D. J. Col. Inter. Sci. 2008, 320, 202.

22. Berberidou, C.; Poulios, I.; Xekoukoulotakis, N. P.; Mantzavinos, D. Appl. Catal. B: Environ. 2007, 74, 63.

23. Yano, J.; Matsuura, J.; Ohura, H.; Yamasaki, S. Ultrason. Sonochem. 2005, 12, 197.

24. Oh, W. C.; Zhang, F. J.; Chen, M. L.; Lee, Y. M.; Ko, W. B. J. Ind. Eng. Chem. 2009, 15, 190.

25. Zhang, K.; Oh, W. C. J. Kor. Cer. Soc. 2009, 46, 561.

26. Oh, W. C.; Chen, M. L. Bull. Kor. Chem. Soc. 2008, 29, 159.

27. Wang, J.; Ma, T.; Zhang, Z. H.; Zhang, X. D.; Jiang, Y. F.; Pan, Z. J.; Wen, F. Y.; Kang, P. L.; Zhang, P. Desalination 2006, 195, 294.

28. Hung, W. C.; Chen, Y. C.; Chu, H.; Tseng, T. K. Appl. Sur. Sci. 2008, 255, 2205.

29. Chen, L. C.; Ho, Y. C.; Guo, W. S.; Huang, C. M.; Pan, T. C.; Electrochimica. Acta 2009, 54, 3884.

30. Zhang, K.; Meng, Z. D.; Ko, W. B.; Oh, W. C. Anal. Sci. Technol. 2009, 22, 254 .

31. Wu, K. Q.; Xie, Y. D.; Zhao, J. C.; Hidaka, H. S. J. Mol. Catal. A 1999, 144, 77.

32. Rincón, A. G.; Pulgarin, C. Appl. Catal. B 2006, 63, 222.

33. Zhang, K.; Oh, W. C. Kor. J. Mater. Res. 2009, 19, 481.

34. Tryba, B.; Morawski, A. W.; Inagaki, M.; Toyoda, M. Chemosphere 2006, 64, 1225.

35. Mrowetz, M.; Pirola, C.; Selli, E. Ultrason. Sonochem. 2003, 10, 247.

36. Shimizu, N.; Ogino, C.; Dadjour, M. F.; Murata, T. Ultrason. Sonochem. 2007, 14, 184.

37. Tu, Y. F.; Huang, S. Y.; Sang, J. P.; Zou, X. W. Mater. Res. Bull. 2010, 45, 224. 